\title{
VALORES, EDUCAÇÃO INFANTIL E DESENVOLVIMENTO MORAL: CONCEPÇÕES DOS PROFESSORES
}

\author{
LIMA, Juliana dos Santos ${ }^{1 *}$; SANTOS, Gilberto Lima dos ${ }^{1^{* *}}$ \\ ${ }^{1}$ Universidade do Estado da Bahia \\ julima17@hotmail.com* \\ glsantos@uneb.br
}

\section{RESUMO}

Na sociedade brasileira atual, a moralidade surge como um dos mais relevantes desafios às práticas educacionais. $O$ estudo tem como objetivo compreender como os professores da educação infantil concebem os valores em relação às suas práticas pedagógicas e ao desenvolvimento moral das crianças. Trata-se de uma pesquisa qualitativa, em que se utiliza a entrevista semiestruturada para a produção de informações. Os participantes são oito educadores da educação infantil. Eles atuam numa escola pública situada em Jaguarari, uma pequena cidade da Bahia. Os resultados mostram que os valores aparecem nos discursos e ações dos professores, assim como nas atividades que eles propõem aos alunos, embora tentem esquivar-se da responsabilidade. Os professores são cuidadosos na relação com os alunos, mas esta relação se processa de modo assimétrico e prioriza o dever, o respeito unilateral e a obediência. Isto significa que os professores assumem uma posição adultocêntrica em suas práticas.

PALAVRAS-CHAVE: Valores morais. Educação infantil. Professor.

\section{VALUES, EARLY CHILDHOOD EDUCATION AND MORAL DEVELOPMENT: TEACHERS' CONCEPTIONS}

\section{ABSTRACT}

In the current Brazilian society, morality is emerging as one of the most important issues challenging educational practices. The goal of the study is to understand how preschool teachers conceive of the values relative to their pedagogical practices and the moral development of children. It is a qualitative research, which uses the semi-structured interview for the production of information. The participants are eight educators of early childhood education in a public school located in Jaguarari, a small city in Bahia. The results show that the values appear in the speeches and actions of teachers, as well as in the activities they propose to students, although they try to wriggle out of responsibility. The professors are careful in relationship with the students, but this relationship is asymmetrical and prioritizes the duty, the unilateral respect and obedience. This means that teachers take an adultcentered position in their practices. KEYWORDS: Moral values. Early childhood education. Teacher.

\section{VALORES, EDUCACIÓN PREESCOLAR Y DESARROLLO MORAL: CONCEPCIONES DE DOCENTES} \section{RESUMEN}

En la actual sociedad brasileña, la moralidad es uno de los retos más importantes para las prácticas educativas. El objetivo de este estudio es entender cómo profesores dan sentido a los valores en la educación preescolar, para examinar sus prácticas de enseñanza y el desarrollo moral de los niños. Es una investigación cualitativa, que utiliza la entrevista semiestructurada para la producción de información. Los participantes son ocho educadores de educación infantil en una escuela pública situada en Jaguarari, una ciudad en Bahía. Los resultados muestran que los valores aparecen en los discursos y las acciones de los docentes, así como en las actividades que proponen a los estudiantes aunque traten de evadir esta responsabilidad. Los profesores son cuidadosos en la relación con los alumnos, pero esta relación sigue siendo asimétrica y prioriza el deber, el respeto unilateral y la obediencia. Esto significa que maestros adoptan una posición centrada en el adulto en sus prácticas.

PALABRAS CLAVE: Valores morales. Educación pré-escolar. Profesor. 


\title{
1 INTRODUÇÃO
}

Nos últimos anos, em especial, a população brasileira tem sido abalada, cotidianamente, por notícias avassaladoras. Essas notícias desenham um cenário dramático e desalentador no país, a partir das tramas políticas que vêm sendo urdidas historicamente nos bastidores e que, agora, são reveladas através de processos investigativos conduzidos pelas instâncias competentes. Nesse cenário, constituído a partir dos espaços institucionais que concretizam as relações entre os três poderes da República, são marcantes os atos ilícitos, a corrupção e o desvio de vultosas somas de recursos financeiros do erário público. O resultado é a precarização de políticas públicas básicas. Tais acontecimentos evocam, inevitavelmente, a noção de "elite predatória" apresentada por Moore Jr. (1987, p. 605):

\begin{abstract}
Portanto, uma elite verdadeiramente predatória é aquela que poucos serviços presta à população subordinada, e extrai para seus próprios fins um excedente grande o suficiente para gerar pobreza em escala maciça, que não existiria caso a população subordinada fosse deixada a seus próprios recursos.
\end{abstract}

Os valores que sustentam a prática da corrupção têm um longo lastro histórico na cultura brasileira. Em Martins (1994, p. 46) encontramos uma noção da abrangência das práticas da corrupção, conforme segue:

\footnotetext{
Rigorosamente, pois, por um conjunto enorme de práticas, condutas e concepções relativas à ideia do favor e da retribuição, pode-se dizer que o conceito de corrupção como se difunde na sociedade brasileira hoje atinge não só alguns políticos: atinge todo o sistema clientelista baseado ainda em fortes componentes da dominação patrimonial. Nesse sentido, quase toda a população, sem disso ter consciência, está de algum modo envolvida em corrupção.
}

Situando-o entre o favor e a corrupção, Barbosa (1992, p. 32) evidencia o famoso jeitinho brasileiro: “[...] é sempre uma forma 'especial' de se resolver algum problema ou situação difícil ou proibida". Este jeitinho brasileiro envolve quase sempre algum tipo de transgressão ou infração. Está entre o favor e a corrupção, sendo seus limites imprecisos. Ora pode ser visto como favor, ora como corrupção, dependendo do contexto. Sobretudo, trata-se de uma prática comum.

As questões apontadas anteriormente remetem, de uma forma ou de outra, aos processos educacionais, tanto no sentido amplo de socialização quanto no sentido estrito de 
escolarização. A educação surge como instrumento indispensável para que a humanidade consolide os valores morais e os princípios éticos que devem reger as relações numa sociedade justa e igualitária. O ensino dos valores morais está entre as ações que promovem a humanização dos seres humanos.

Goergen (2005) aponta duas vertentes teóricas que relacionam moral e educação, uma individualista e outra social. Para a vertente social, as normas morais são construídas na dimensão coletiva e impostas aos indivíduos, que, por sua vez, não tem poderes para influenciá-las, pois não há espaço para a autonomia e a responsabilidade do sujeito. A vertente social resultou num modelo de educação baseado no disciplinamento, que vigorou por muito tempo no campo religioso e permanece, ainda, na educação laica. Para a vertente individualista, pode agir com responsabilidade ou competência moral aquele que se orienta pela ideia do bem, que só pode ser alcançada através de um processo reflexivo pessoal e autônomo.

Müller e Alencar (2012, p. 456) defendem a vertente individualista “[...] como o processo pelo qual os valores deixam de ser leis impostas por agentes externos e convertem-se em diretrizes internas, legitimadas pela própria pessoa". Esta compreensão lembra a perspectiva do desenvolvimento moral construída anteriormente por Piaget $(1999,2015)$. Para este autor, os dois primeiros anos de vida são caracterizados pela anomia ou ausência de normas. A anomia é seguida pela heteronomia e esta, por sua vez, serve de base para o surgimento da autonomia. Neste modelo, os primeiros sentimentos morais se produzem em articulação com o respeito unilateral. Este é uma combinação de afeição e temor que se apresenta em relações assimétricas, como as que se estabelecem entre adultos e crianças. São sentimentos intuitivos, espontâneos e compatíveis com o pensamento mágico, típico de crianças com idade entre dois e sete anos.

Sendo assim, a moralidade que se constitui nesse momento da vida é calcada, simultaneamente, na vontade dos adultos e na obediência da criança. A vontade dos adultos configura a noção do bem e as regras propriamente ditas. Esta moralidade heterônoma fundamenta o aparecimento da moralidade autônoma, à medida que o respeito unilateral possibilita o desenvolvimento do respeito mútuo. O respeito mútuo é engendrado nas relações em que afeição, colaboração e sentimento de justiça se conectam numa articulação lógica. Pode-se dizer que a moralidade heterônoma conduz ao sentimento do dever e a moralidade autônoma

Educação \& Formação, Fortaleza, v. 3, n. 8, p. 153-170, maio/ago. 2018

DOI: http://dx.doi.org/

http://seer.uece.br/redufor 
conduz ao sentimento do bem, mais interiorizado e tendente à constituição de convicções orientadoras do agir individual (PIAGET, 1999, 2015).

Se a autoética não é uma dádiva e precisa ser construída, como Morin (2011) afirma, essa construção remete direta e necessariamente aos processos de educação. Para Boff (2011, p. 37), a ética diz respeito a "[...] concepções de fundo acerca da vida, do universo, do ser humano e de seu destino, estatui princípios e valores que orientam pessoas e sociedade". Isto é, uma pessoa é ética quando se orienta por princípios e convicções internalizados. Diz-se, então, que tem caráter e boa índole. Por sua vez, a moralidade faz parte da vida concreta, cotidiana:

\footnotetext{
Trata-se da prática real das pessoas que se expressam por costumes, hábitos e valores culturalmente estabelecidos. Uma pessoa é moral quando age em conformidade com costumes e valores consagrados. Estes podem, eventualmente, ser questionados pela ética. Uma pessoa pode ser moral (segue os costumes até por conveniência), mas não necessariamente ética (obedece a convicções e princípios). (BOFF, 2011, p. 37).
}

Boff $(2011$, p. 9) afirma que “[...] há uma constatação indiscutível de aterradora crise ética e moral em todas as partes, atingindo o coração da humanidade". Isto é, aquilo que era claramente distinto nas éticas tradicionais - por exemplo, o certo e o errado, o bom e o ruim -, hoje não é mais. Suas fronteiras tornaram-se nebulosas. Morin (2011, p. 39) esclarece que "[...] as éticas tradicionais eram integradas e integrantes: estavam integradas em uma comunidade religiosa, familial, cívica, nacional", onde os conceitos de bem e de mal, de verdadeiro e de falso eram absolutamente evidentes e consentidos por todos. Contudo, numa sociedade individualista, marcada pelo imperativo da liberdade, diversas posições morais podem ser assumidas pelo indivíduo, dependendo da situação. Os antigos e amplos compartilhamentos cedem lugar à heterogeneidade.

Essa crise nos fundamentos éticos e morais tensiona as relações sociais. Constitui-se um panorama em que as pessoas tendem a priorizar seus próprios interesses, em detrimento do direito e da justiça (BOFF, 2011). Nesse contexto, Morin (2011) apresenta a seguinte questão: como fundamentar uma ética na liberdade individual, quando os valores não são compartilhados por todos? De acordo com Gonçalves e Bock (2003, p. 96), “[...] compreender o indivíduo é compreender ao mesmo tempo a relação indivíduo-sociedade". Isso significa que indivíduo e sociedade são reciprocamente constitutivos. As interações entre os indivíduos produzem a cultura e a educação, e estas, simultaneamente, conferem aos indivíduos suas características humanas. Nas sociedades capitalistas, esse movimento dialético é orientado, predominantemente, por 
valores individualistas. A vantagem pessoal e a competitividade triunfam sobre a cooperação, a solidariedade e o respeito mútuo em muitos momentos e espaços sociais.

Compartilhamos com Müller e Alencar (2012) o entendimento de que o desenvolvimento moral tende a ser mais promissor em espaços onde há o incentivo ao diálogo, ao exercício da autonomia e da criticidade e, também, a valorização de virtudes. Família, igreja, escola, organizações do trabalho, círculos de amizade, entre outros, são exemplos desses espaços. Diante de tal amplitude, o presente estudo focaliza a escola, pois, esta se constitui como "[...] espaço privilegiado para a construção paulatina e contextualizada de um conjunto de valores humanos e de competências que permitem enfrentar eficazmente as situações e desafios sociomorais e éticos que nele surgem" (BARRIOS; MARINHO-ARAÚJO; BRANCO, 2011, p. 96). Durante o período da educação infantil, as crianças são inseridas em situações que contribuem muito para aprimorar sua participação nas práticas sociais. Por assumir tal consideração, para Campos et al. (2011, p. 28):

\footnotetext{
O pressuposto adotado é que a frequência a uma creche ou pré-escola de qualidade faz a diferença na vida das crianças não só em se tratando do impacto positivo em sua trajetória escolar posterior, mas também, e principalmente, no que diz respeito à natureza das experiências vividas durante o tempo em que frequentam estas instituições, possibilitando uma plena vivência de sua infância e ampliando suas possibilidades de compreensão e interação com o mundo e pessoas ao seu redor.
}

Os Parâmetros Nacionais de Qualidade para a Educação Infantil (BRASIL, 2006) destacam a relevância do trabalho com valores desde o início da educação básica, tendo em vista a formação da criança para o exercício da autonomia, da responsabilidade, da solidariedade e do respeito ao bem comum. Na educação infantil, a criança é inserida na dinâmica das relações sociais que se desenvolvem fora dos domínios da família. Essas interações entre colegas e adultos são fundamentais, uma vez que ampliam o contexto de circulação de crenças e valores morais que são ativamente processados pela criança. Dessa forma:

\footnotetext{
Dependendo da natureza do ambiente sociomoral, a criança aprende que o mundo das pessoas é coercitivo ou cooperativo, individualista ou solidário. A relação adulto-criança é fundamental nesse processo, uma vez que é o adulto quem tem a possibilidade de mediar o ambiente sociomoral, organizando as atividades e relacionando-se com as crianças de modo predominantemente autoritário ou democrático. (BARRIOS; MARINHO-ARAÚJO; BRANCO, 2011, p. 96).
}

Em consonância com essa compreensão, pode-se afirmar a centralidade das crianças na construção de uma educação voltada para o desenvolvimento moral, pois a educação das novas

Educação \& Formação, Fortaleza, v. 3, n. 8, p. 153-170, maio/ago. 2018

DOI: http://dx.doi.org/

http://seer.uece.br/redufor 
gerações repercute diretamente na educação da sociedade como um todo. Neste sentido, o exercício que elas possam realizar no campo dos direitos, sendo adequadamente escutadas e consideradas, ganha relevo especial. Segundo Barrios, Marinho-Araújo e Branco (2011, p. 95), "[...] se as crianças não têm seus interesses levados em consideração e trabalhados em situações de negociação, restam-lhes poucas oportunidades para exercerem sua autonomia através de escolhas e de um posicionamento mais livre e ativo".

A falta de participação da criança pode resultar na superficialidade do processo de formação pessoal. O diálogo, a divisão de responsabilidades e a troca de experiências entre o professor e o aluno contribuem efetivamente para a construção da personalidade moral. Quanto mais frequentes e mais diversas forem as possibilidades de trocas entre as pessoas, mais amplo poderá ser o exercício da reciprocidade, pois, esta relação mútua possibilita à criança refletir sobre ações que são válidas não apenas para ela, mas, também para o outro (MENIN, 2002).

De acordo com Barrios, Marinho-Araújo e Branco (2011), apesar da significância de uma educação voltada para os valores, há instituições educativas nas quais os professores a consideram apenas enquanto criação de regras e normas, sem atentar para o caráter intrínseco dos processos pedagógicos. A este respeito, Menin (2002) salienta a existência de escolas que adotam uma postura relativista em relação à educação em valores, escolas que não se posicionam efetivamente para o desenvolvimento dos mesmos, havendo predomínio do entendimento de que tudo é relativo e de que não há, a rigor, uma posição mais correta que a outra.

Uma posição relativista em educação, sob a ótica dos valores, pode permitir controvérsias num mesmo ambiente educacional, onde valores e contravalores podem coexistir e nem sempre serem frutos de reflexão. Nesta perspectiva, os professores que incentivam a competitividade são orientados por uma visão capitalista hegemônica e aqueles que estimulam o respeito mútuo e o cooperativismo visam à formação de sujeitos que colaborem na construção de uma sociedade mais justa e igualitária. Isto não significa, necessariamente, que os primeiros ajam de má fé. As ideologias se encarregam de dificultar a tomada de consciência por parte dos indivíduos imersos numa determinada realidade social, de acordo com Chauí (2016).

Para Barrios, Marinho-Araújo e Branco (2011), os atores que compõem o contexto escolar precisam ter consciência do seu importante papel no desenvolvimento moral do ser humano, desenvolvimento que não pode ficar restrito ao contexto familiar e não pode ser reduzido à 
manutenção da ordem, da disciplina e do conformismo. Por conseguinte, se quisermos formar alunos que sejam capazes de refletir sobre os valores existentes, que sejam críticos e criativos na construção de contra valores, capazes de escolher valores que tornem a vida social mais justa, é preciso que a escola crie situações que oportunizem a ocorrência dessas escolhas, reflexões e críticas (MENIN, 2002). Afinal, como ensinar o respeito mútuo, a solidariedade e a justiça sem atividades que os promovam e, ao mesmo tempo, provoquem processos reflexivos?

Uma pesquisa realizada por Souza e Placco (2008, p. 754), na qual objetivou-se identificar os valores existentes na escola, mostrou que há, neste ambiente, "[...] pensamentos, estudos, práticas e ações conscientes implicadas e éticas concorrendo com outras muitas vezes imorais". As autoras ressaltam ainda que, em se tratando do ensino-aprendizagem de conteúdos acadêmicos, com frequência os professores e a escola buscam a "autoabsolvição", mas, que, no caso da formação moral, em relação à qual a família tende a ser culturalmente responsabilizada, ocorre uma verdadeira esquiva à responsabilidade. Essa esquiva dos professores inviabiliza, por conseguinte, a construção de valores positivos.

Em outra pesquisa, Dias (2005) buscou compreender o que pensam os professores sobre educação moral e autonomia na educação infantil. Como resultado, deparou-se com concepções abstratas, individualizantes e descontextualizadas a orientar práticas espontaneístas, sem clareza acerca dos objetivos. Por sua vez, Nunes (2009) analisou as interações havidas entre uma professora e as crianças da educação infantil, tentando identificar relações entre práticas pedagógicas e educação moral. Ela constatou que as relações entre professora e alunos são assimétricas, baseadas no disciplinamento, no estabelecimento de normas e regras e na transmissão unilateral de valores.

Da leitura dos estudos que encontramos na literatura, podemos depreender que, embora as experiências cotidianas sejam, em certa medida, imprevisíveis, exigindo assim uma boa dose de improvisação e criatividade, a prática pedagógica voltada para a educação moral precisa ser planejada e sistemática, e isso, evidentemente, implica exigências à formação dos professores. Quanto à margem de imprevisibilidade, Morin (2011, p. 43) assinala: "Tem-se, sem cessar, o problema de que, efetivamente, as intenções não bastam e que, além disso, mesmo as boas estratégias não são suficientes, pois podem sobrevir momentos em que os acontecimentos contrariam as intenções, e em que a própria estratégia se revela inoperante". 
Ou seja, por outro lado, a despeito da necessidade e da efetividade do planejamento, sempre há uma margem de incerteza quanto aos resultados de nossa ação. Assim, estar consciente disso pode não apenas amenizar possíveis sentimentos de frustração, mas, facilitar o predomínio de processos reflexivos, para que se aprenda no decorrer das vivências, ao mesmo tempo em que se reorientam tanto as atuações quanto os procedimentos.

Diante de tudo que foi exposto, e considerando a relevância social e cultural do tema, concluímos que ainda são necessários estudos que ampliem o entendimento de como as concepções e práticas dos professores se articulam, no que tange ao desenvolvimento moral das crianças que iniciam o processo de escolarização. Sendo assim, o presente estudo buscou responder às seguintes perguntas: como os professores da educação infantil concebem os valores e suas implicações nas atividades de ensino e no desenvolvimento moral das crianças? Como os valores e a educação moral ganham efetividade em suas práticas de ensino? Sendo assim, o objetivo consistiu em compreender como os professores da educação infantil concebem os valores em relação às suas práticas de ensino e ao desenvolvimento moral das crianças.

\section{MÉTODO}

O presente estudo adota uma abordagem qualitativa e prioriza aspectos psicossociais. Foi desenvolvido numa escola de educação infantil, situada em Jaguarari, cidade do interior da Bahia. Esta escola possui cerca de 245 alunos, distribuídos nos turnos matutino e vespertino. 0 seu alunado está na faixa de 3 a 6 anos de idade. A maioria pertence a famílias de baixa renda, beneficiárias dos programas assistenciais do Governo Federal.

\subsection{Participantes}

Os participantes da pesquisa foram oito docentes (professores e auxiliares) que atuam na referida escola, selecionados por conveniência e disponibilidade. Sete são do sexo feminino e um do sexo masculino, com idade variando entre 20 e 54 anos. Eles são responsáveis por crianças de 4 a 6 anos de idade. Alguns apresentam formação de nível médio e outros de nível superior. A experiência profissional em unidades de educação infantil varia de um a 23 anos. 


\subsection{Instrumento e procedimentos}

As informações foram produzidas através de entrevista semiestruturada. As entrevistas versaram sobre os seguintes tópicos: o crédito dado ou não à educação quanto ao desenvolvimento moral; o incentivo aos valores por parte dos docentes; a resolução de problemas no ambiente escolar; a formulação de regras para os alunos; e a relação entre a ação docente e o desenvolvimento moral das crianças.

As entrevistas foram realizadas individualmente, em horários escolhidos pelos participantes, numa sala disponibilizada pela coordenação da instituição. Com duração média de trinta minutos, as entrevistas foram gravadas em áudio. Seus conteúdos foram transcritos na íntegra, logo após a realização de cada uma delas. Neste caso, a fidelidade à fala do entrevistado foi tomada em consideração. Para assegurar o anonimato dos entrevistados, seus nomes são fictícios. Vale ressaltar que foram adotados todos os cuidados e procedimentos éticos requeridos para a pesquisa com seres humanos, inclusive a submissão ao comitê de ética, conforme a legislação em vigor no país.

No processo de análise, as entrevistas foram lidas muitas vezes, após a transcrição, até que a percepção da totalidade ficasse suficientemente clara ao ponto de possibilitar a emergência de categorias organizadoras. Então, as informações foram organizadas em três categorias emergentes, a saber: interação entre professor e aluno; atividades desenvolvidas; e concepções de valor entre os professores. Ao longo do processo de categorização das informações, buscou-se apreender todas as concepções e significações apresentadas pelos professores, que foram, então, configuradas, estabelecendo-se um diálogo teórico com vários autores.

\section{RESULTADOS}

\subsection{Interação entre professor e aluno}

Acredita-se que as interações entre professor e aluno são fundamentais para o desenvolvimento moral, em função de suas características e do papel do professor como mediador

Educação \& Formação, Fortaleza, v. 3, n. 8, p. 153-170, maio/ago. 2018

DOI: http://dx.doi.org/

http://seer.uece.br/redufor 
do desenvolvimento da criança (BARRIOS; MARINHO-ARAÚJO; BRANCO, 2011). Sendo assim, destacamos o entendimento que os docentes apresentam acerca dessa importante relação:

Então, o professor, a partir do momento que ele trata os alunos com respeito, que ele fala com o aluno de maneira que ele não fira o aluno, se ele não grita com o aluno, se ele pede, por favor, se ele quer ensinar em questões de valores, ele tá [sic] ensinando, porque o exemplo muitas vezes vale mais do que as falas. (PROFESSORA MADALENA).

A compreensão desta fala remete à suposição de Müller e Alencar (2012, p. 465), as quais afirmam que "[...] é por meio da cooperação, do respeito mútuo e do diálogo que a construção da personalidade moral pode ser efetuada". A professora entrevistada aponta duas alternativas que se apresentam à sua atuação, com vistas à resolução de conflitos entre alunos. Em ambas, tende a expressar seus valores e a afetar diretamente os alunos, positiva ou negativamente, conforme o caso. Porém, o que podemos entrever na reflexão da Professora Madalena ainda não é a possibilidade do diálogo. Há um posicionamento prescritivo da professora, que se apresenta como modelo a ser imitado. Assim, ela indica que estabelece uma relação assimétrica, ainda que cuidadosa, com seu aluno. Outra entrevistada, por sua vez, diz: "Gritar muito, às vezes, não é bom, não [...] tem professores que diz que quanto mais grita mais o menino vai obedecer. Não, às vezes, acaba o menino ficando violento, acaba relaxando" (PROFESSORA RUTHY).

A ponderação da Professora Ruthy, ao criticar os excessos na ação repressora de seus colegas, ao mesmo tempo que reafirma a importância do modelo, remete-nos a uma educação moral voltada para os princípios autoritários, em que a obediência é tida como um ideal a ser alcançado. Atualmente, em virtude das diversas mudanças sociais, esses princípios têm sido alvo de profundos questionamentos. Contudo, eles persistem em muitas práticas diárias no ambiente escolar, apontando a necessidade de um posicionamento crítico, consciente e ético frente às práticas pedagógicas (BARRIOS; MARINHO-ARAÚJO; BRANCO, 2011). Nessa perspectiva, outra participante explicita, ainda, como tem sido a atuação dos professores em sua escola: “ $A$ gente sempre ensina para eles respeitar o coleguinha, respeitar os mais velhos, sempre eu falo com eles tentando formar atitudes nessas crianças, para futuramente continuar sendo pessoas de bem, dignos para saber se comportar na sociedade" (PROFESSORA MARIA).

Educação \& Formação, Fortaleza, v. 3, n. 8, p. 153-170, maio/ago. 2018

DOI: http://dx.doi.org/

http://seer.uece.br/redufor 
As declarações focalizadas até aqui evidenciam que os docentes privilegiam o aconselhamento, ao interagirem com as crianças, com o intuito de advertir, persuadir e, assim, estimular atitudes de respeito, obediência e de senso de dever comum. Isto fica ainda mais claro na seguinte assertiva:

[...] a forma mais fácil de você transformar uma pessoa para melhor é conversando com ela, mostrando que aquilo que ela tá fazendo não é certo e procurando meios para incentivar o caminho melhor, porque a gente não vive numa ilha, a gente vive em sociedade, a gente precisa se enturmar e precisa aprender com as diferenças, a gente precisa se aliar às diferenças. (PROFESSORA ESTER).

A expressão da Professora Ester realça, do seu ponto de vista, a relevância do diálogo para o desenvolvimento dos valores e, consequentemente, para a construção da moralidade. Entretanto, é possível notar que a comunicação efetivada na interação com as crianças é unilateral. A prática dos professores consiste em prescrever atitudes e comportamentos que eles próprios valorizam. Não há a concessão de uma escuta à criança. Isto contraria a indicação de Dias (2005), por exemplo, quando afirma que um processo pedagógico de natureza dialógica é fundamentado no respeito mútuo, na cooperação e no desenvolvimento da capacidade de reflexão crítica sobre as questões éticas e sobre o agir humano no mundo sociomoral. É desse modo que a prática pedagógica pode contribuir para o desenvolvimento de homens e mulheres mais justos, capazes de atuar criticamente em diferentes situações, avaliando e reavaliando suas ações.

\subsection{Atividades desenvolvidas}

As atividades desenvolvidas pelos docentes tendem a demonstrar o seu comprometimento, ou não, com uma educação em valores. Como Müller e Alencar (2012, p. 465) observam, “[...] é certo que os procedimentos de educação moral são muitos e variados [...]". Sendo assim, vejamos as expressões dos participantes apresentadas a seguir:

\footnotetext{
A Educação Infantil aqui, em nosso município, ela é muito conteudista, muito! Então você tem que ensinar todas as letras, todos os numerais... claro que eles têm que ter noção, mas a partir do momento que você vai agregando nas histórias que você conta, você tá [sic] trabalhando os valores. Então numa brincadeira deles, você tá [sic] trabalhando com os valores, nessa questão de saber ganhar, de saber perder, nos jogos. Na brincadeira, na questão de respeitar a vez do outro. (PROFESSORA MADALENA).
}

Educação \& Formação, Fortaleza, v. 3, n. 8, p. 153-170, maio/ago. 2018

DOI: http://dx.doi.org/

http://seer.uece.br/redufor 
Aqui temos a indicação de que a narração de histórias, os jogos e as brincadeiras surgem como atividades propícias à emergência dos valores. Porém, lembramos que, em momentos de conflito, os professores lançam mão da atividade de aconselhamento. Anteriormente, tínhamos visto que o respeito e a obediência são valores destacados. Agora, podemos acrescentar a tolerância e o comedimento. Contudo, as oportunidades destinadas aos valores nas atividades planejadas cotidianamente parecem ser bastante escassas:

Eu queria dar mais atenção para esses valores, mas infelizmente, como eles estão aprendendo a ler e a escrever, o tempo é curto, quando a gente vê, já terminou a aula e a gente se apega muito no ler e no escrever [...] Eu sei que o ler e o escrever é importante, mas o trabalhar os valores é muito importante. (PROFESSORA JOANA).

Apesar de demonstrarem preocupação com o desenvolvimento integral do aluno, é possível perceber, nas duas falas precedentes, o quanto o sistema educacional tem priorizado o ensino da leitura e escrita em detrimento dos valores. A esse respeito, Barrios, Marinho-Araújo e Branco (2011) advertem que, apesar da escola ter um discurso inovador referente à educação integral da criança, a sua prática está voltada para os princípios norteadores da educação tradicional, em que educar é transmitir ou fornecer determinados conhecimentos e significados culturais, sem a sua participação ativa nesse processo. Por conseguinte, em virtude da complexidade, o desenvolvimento dos valores é concebido, apenas, como a criação de regras e normas, conforme afirmaram dois entrevistados:

\footnotetext{
Tem sempre as regrinhas de convivência, como não brigar, não bater o colega... a gente cria, né?! Respeitar o colega, não jogar lixo na sala [...]. (PROFESSORA MARIA).

Tem a tabela do comportamento, é essencial aqui. Tipo assim, quem se comporta durante a semana todinha leva bolinha, quem não se comportar leva $X$. (PROFESSOR PAULO).
}

Os discursos dos professores revelam que regras e normas são estabelecidas a fim de manter a ordem e o bom relacionamento entre as crianças no ambiente escolar. Todavia, essas regras são introduzidas na situação de forma impositiva e, contrariando as expectativas dos professores, as crianças não as assumem facilmente. Para Menin (2002, p. 95), "[...] valores impostos por uma autoridade são aceitos por temor enquanto perdurar o controle dessa autoridade e deixam de ser assumidos como valores no momento em que a força do controle é enfraquecida". Sobretudo, evidencia-se que, ao formular as normas a serem seguidas pelas 
crianças, a motivação dos professores é fundada numa lógica disciplinar que é inerente à pedagogia tradicional.

As narrativas dos professores permitem perceber que rituais religiosos também são elementos constitutivos das práticas educativas. Vejamos o que dizem alguns entrevistados a respeito de sua rotina:

\begin{abstract}
Na segunda-feira tem a hora da novidade, que é hora que eles vão se colocar tudo que ele fez durante a semana, depois tem as musiquinhas, tem a parte da oração, que é a hora que eu vou tá [sic] falando pra gente pedir proteção a Deus, que a gente tá rezando, pedindo sabedoria. (PROFESSORA JOANA).
\end{abstract}

Primeiro a gente chega, canta, aí tem a chegada para atender os pais, receber as crianças, depois a gente faz a oração, depois entra no conteúdo. (PROFESSOR PAULO).

As descrições da Professora Joana e do Professor Paulo remetem a autores como Boff (2011), por exemplo, que aponta a religião como uma das fontes que orientam ética e moralmente as sociedades desde tempos remotos. Assim sendo, apesar do discurso laico que permeia as instituições de ensino, muitos educadores ainda adotam práticas religiosas no intuito de estimular posturas de cunho moral ou ético.

\title{
3.3 Concepções de valor entre os professores
}

Com base no conteúdo discutido nos itens anteriores, podemos depreender que a educação em valores ocorre através das ações do educador e das atividades que este oportuniza às crianças nos espaços escolares. Essas práticas, de uma forma ou de outra, representam e expressam as concepções que norteiam o exercício profissional dos professores. Por isso, é pertinente que as concepções de valores dos professores sejam tomadas em consideração, conforme segue:

Valores são atos que a gente consegue ensinados a partir de dentro de casa, da família, porque as pessoas mais velhas passavam muitos valores pra gente, a gente complementava na escola. (PROFESSORA MARIA).

A partir desses valores é que a gente vai formar cidadãos mais participativos, mais criativos, esses valores, eles vão formar personalidade da criança, se for trabalhados [sic] não só na escola, esses valores tem que ser trabalhados em casa, nós professores só vamos complementar. (PROFESSORA JOANA).

Educação \& Formação, Fortaleza, v. 3, n. 8, p. 153-170, maio/ago. 2018

DOI: http://dx.doi.org/

http://seer.uece.br/redufor 
As participantes reconhecem a importância dos valores para a constituição da individualidade, sua pertença ao agir, e remetem-nos, prontamente, em suas bases constitutivas, ao âmbito familiar e aos aprendizados condicionados pelas relações intergeracionais. Desse modo, elas restringem à escola apenas o trabalho de mantê-los ou complementá-los. Autores como Souza e Placco (2008) afirmam que muitos docentes "desresponsabilizam-se" desse dever moral, o que implica, principalmente, em aterem-se à conservação dos valores familiares. Contudo, cabe ressaltar que a desresponsabilização não significa isenção. Ainda que os professores não tenham sempre consciência disso, suas práticas pedagógicas estão inevitavelmente impregnadas de valores potencialmente capazes de afetar as crianças.

Sobre a importância dos valores, uma das participantes assinala o seguinte: "Acho que os valores todos são importantes, mas tem uns que se destacam mais, principalmente a gente que trabalha com criança, com educação Infantil" (PROFESSORA ESTER). Do ponto de vista dos professores, os valores são passíveis de gradação e esta se relaciona diretamente com o ambiente, com a situação e com os atores envolvidos. Vimos, no primeiro item desta seção, que o respeito e a obediência são os valores especialmente destacados pelos professores. Para Neff e Helwig (2002), são vários os fatores que levam as pessoas a conceber os valores ou raciocinar moralmente de modo diferenciado. Por exemplo: questões ligadas à justiça, ao bem-estar, aos direitos, às regras, à autoridade, às tradições, à posição social, à situação e à prerrogativa pessoal.

Os discursos e narrativas dos participantes deste estudo permitem perceber que a educação moral, em sua escola, não tem sido objeto de discussão e nem está inserida em planejamentos. Portanto, é algo que ocorre de modo pouco sistematizado, como resposta mais ou menos improvisada às ocorrências cotidianas. Isto também foi identificado por Dias (2005). De todo modo, os valores aparecem imbricados nos discursos e ações dos professores, assim como nas atividades que propõem aos alunos. Os professores são cuidadosos na relação com seus alunos, mas esta relação continua sendo assimétrica e prioriza o dever, o respeito unilateral e a obediência, o que caracteriza a moralidade heterônoma, de acordo com Piaget $(1999,2015)$. Estes achados são coincidentes com os de Nunes (2009). O equacionamento do cuidado e da assimetria resulta em imposições sutis, baseadas na persuasão, ao invés da truculência coercitiva, que é hoje socialmente indesejável. Em outras palavras, configuramos um autoritarismo sutil, persuasivo e adultocêntrico. 
Além disso, os resultados nos possibilitam apontar as atividades nas quais há um predomínio de atuação intencional dos professores com foco na moralidade: jogos, brincadeiras, narração de histórias e aconselhamento. Destacamos, sobretudo, o aconselhamento, pois este é o formato de atividade preferido pelos professores nos momentos em que as crianças vivenciam situações de conflito ou violam a ordem.

Em síntese, as práticas de ensino dos participantes do estudo são compatíveis com o modelo inspirado na vertente teórica social, que é baseado no disciplinamento (GOERGEN, 2005). Para que a escola promova o desenvolvimento da moralidade autônoma, será necessário que os professores propiciem aos alunos oportunidades para que, através do diálogo, exteriorizem seus entendimentos e exercitem a cooperação, a reflexividade, a empatia e a consideração mútua. Em momentos assim, sempre vale lembrar um ensinamento de Vigotski (2000, p. 117): “[...] o ‘bom aprendizado' é somente aquele que se adianta ao desenvolvimento”.

\section{CONSIDERAÇÕES FINAIS}

Tomando como ponto de partida as perguntas que suscitaram este trabalho, os resultados obtidos indicaram como os professores significam ou concebem os valores, quando os relacionam às suas práticas pedagógicas e ao desenvolvimento moral dos seus alunos. Foi possível perceber que o sistema educacional, muitas vezes, dificulta ou impede que os docentes desenvolvam estratégias ou atividades que viabilizem o desenvolvimento integral da criança, uma vez que exige do professor, prioritariamente, ações relacionadas à leitura e à escrita. Consequentemente, o desenvolvimento moral é invisibilizado, em certa medida.

Além disso, os professores tendem a se esquivar desse tipo de problemática, em sua prática, apesar de realçarem a importância dos valores na formação dos alunos. Para isto, apelam à justificativa de que compete à escola apenas manter ou complementar a educação moral, sendo este dever essencial da família. Entretanto, evitar que os valores permeiem os discursos e ações é algo inviável. Sendo assim, os professores acabam por afetar as crianças com suas convicções, ainda que isto não seja planejado e nem mesmo implique uma escolha deliberada. Além disso, os conflitos e atritos entre alunos acontecem, e os professores são compelidos a intervir, introduzindo questões relativas à moralidade nessas situações. 
Nessas vivências do cotidiano, os professores não atentam para a posição privilegiada da escola, diante da possibilidade de promover a transição da moralidade heterônoma para a moralidade autônoma. Essa transição pode carrear implicações fundamentais para o desenvolvimento e para a constituição do indivíduo, no que concerne ao exercício da cidadania, da cooperação e da solidariedade; ao implemento do pensamento lógico e do senso de justiça; e ao desenvolvimento de convicções e princípios éticos. Ao invés disso, e a despeito dessas implicações, os professores têm optado pela manutenção da heteronomia, hipervalorizando a obediência e o dever.

Para manter a moralidade heterônoma, os professores tentam se apresentar como modelos para as crianças e, ao mesmo tempo, lançam mão de uma pedagogia diretiva, não mais nos moldes da imposição francamente autoritária, mas, configurada pela sutileza da persuasão adultocêntrica. Isto se torna bastante evidente na referência ao aconselhamento, que é, talvez, além da narração de histórias e das brincadeiras, a atividade na qual se empenham com mais clareza de propósito na tarefa de inculcar valores. Em outras palavras, as opções dos professores são coerentes com o ideário tradicional que fundamenta sua prática pedagógica.

Sendo assim, o presente estudo sugere a necessidade de saber, através de novos empreendimentos investigativos, se essa perspectiva assumida pelos professores entrevistados é algo mais abrangente no sistema público de ensino e o que pode ser feito para mudar essa tendência a formar gerações para a conformidade e para a precarização da reflexividade. Preliminarmente, evidencia-se a necessidade de que os professores passem a atuar com base no conhecimento científico, ao invés de seguirem o senso comum e suas tradições educacionais. Isto implica diretamente sua formação acadêmica e exigirá, dentre outras coisas, que eles se apropriem dos relevantes estudos existentes, hoje, acerca da infância. Por isso mesmo, sugere-se que se dê curso a uma profunda e sistemática reflexão acerca da relação de oposição entre, de um lado, a manutenção da heteronomia, baseada no adultocentrismo e na sutilização do autoritarismo e, de outro lado, os ideais democráticos e o reconhecimento das competências e dos direitos das crianças nas últimas décadas.

para finalizar, cabe assinalar que o que está em jogo não é a mera atribuição de uma missão redentora à escola, mas o reconhecimento de que, independentemente de seus principais atores terem consciência disso, ela desempenha papel importante e irrecusável na 
formação moral daqueles que a vivenciam. Mais do que isso, cabe evidenciar que o lastro cultural a que nos referimos no início é sempre passível de transformação, como o é tudo aquilo que é social e historicamente constituído.

\section{REFERÊNCIAS}

BARBOSA, L. O jeitinho brasileiro: a arte de ser mais igual do que os outros. Rio de Janeiro: Campus, 1992.

BARRIOS, A.; MARINHO-ARAÚJO, C. M.; BRANCO, A. U. Formação continuada do professor: desenvolvendo competências para a promoção do desenvolvimento moral. Psicologia Escolar $e$ Educacional, São Paulo, v. 15, n. 1, p. 91-99, 2011.

BOFF, L. Ética e moral: a busca dos fundamentos. 7. ed. Petrópolis: Vozes, 2011.

BRASIL. Parâmetros nacionais de qualidade para a educação infantil. Brasília, DF: MEC, 2006.

CAMPOS, M. M. et al. A qualidade da educação infantil: um estudo em seis capitais brasileiras. Cadernos de Pesquisa, São Paulo, v. 41, n. 142, p. 20-54, 2011.

CHAUÍ, M. S. Ideologia e educação. Educação e Pesquisa, São Paulo, v. 42, n. 1, p. 245-257, 2016.

DIAS, A. A. Educação moral e autonomia na educação infantil: o que pensam os professores. Psicologia: Reflexão e Crítica, Porto Alegre, v. 18, n. 3, p. 370-380, 2005.

GOERGEN, P. Educação e valores no mundo contemporâneo. Educação \& Sociedade, Campinas, v. 26, n. 92, p. 983-1011, 2005.

GONÇALVES, M. G.; BOCK, A. M. B. Indivíduo-sociedade: uma relação importante na psicologia social. In: BOCK, A. M. B. (Org.). A perspectiva sócio-histórica na formação em psicologia. Petrópolis: Vozes, 2003. p. 41-99.

MARTINS, J. S. O poder do atraso. São Paulo: Hucitec, 1994.

MENIN, M. S. S. Valores na escola. Educação e Pesquisa, São Paulo, v. 28, n. 1, p. 91-100, 2002.

MOORE JR., B. Injustiça: as bases sociais da obediência e da revolta. São Paulo: Brasiliense, 1987.

MORIN, E. Ética e sociedade. In: PENA-VEGA, A.; ALMEIDA, C. R. S.; PETRAGLIA, I. (Org.). Edgar Morin: ética, cultura e educação. 4. ed. São Paulo: Cortez, 2011. p. 39-45.

Educação \& Formação, Fortaleza, v. 3, n. 8, p. 153-170, maio/ago. 2018

DOI: http://dx.doi.org/

http://seer.uece.br/redufor 
MÜLLER, A.; ALENCAR, H. M. Educação moral: o aprender e o ensinar sobre justiça na escola. Educação e Pesquisa, São Paulo, v. 38, n. 2, p. 453-468, 2012.

NEFF, K.; HELWIG, C. A constructivist approach to understanding the development of reasoning about rights and authority within cultural contexts. Cognitive Development, Amsterdam, v. 17, p. 1429-1450, 2002.

NUNES, A. M. B. G. Desenvolvimento moral e práticas pedagógicas na educação infantil: um estudo sociocultural construtivista. 2009. 255 f. Dissertação (Mestrado em Processos de Desenvolvimento Humano e Saúde) - Programa de Pós-Graduação em Processos de Desenvolvimento Humano e Saúde, Universidade de Brasília, Brasília, DF, 2009.

PIAGET, J. Os procedimentos da educação moral. In: MACEDO, L. (Org.). Cinco estudos de educação moral. 2. ed. São Paulo: Casa do Psicólogo, 1999. p. 1-36.

PIAGET, J. Seis estudos de psicologia. 25. ed. Rio de Janeiro: Forense Universitária, 2015.

SOUZA, V. L. T.; PLACCO, V. M. N. S. O auto-respeito na escola. Cadernos de Pesquisa, São Paulo, v. 38, n. 135, p. 729-755, 2008.

VIGOTSKI, L. S. A formação social da mente: o desenvolvimento dos processos psicológicos superiores. 6. ed. São Paulo: Martins Fontes, 2000.

Recebido em 27 de julho de 2017.

Aceito em 2 de fevereiro de 2018. 